\title{
High-resolution maps of Coda $Q$ in Japan and their interpretation by the brittle-ductile interaction hypothesis
}

\author{
Anshu Jin and Keiiti Aki* \\ Association for the Development of Earthquake Prediction and National Research Institute for Earth Sciences and Disaster Prevention
}

(Received January 18, 2005; Revised March 16, 2005; Accepted March 18, 2005)

\begin{abstract}
Using seismograms recorded at $582 \mathrm{Hi}$-net stations for earthquakes located within $30 \mathrm{~km}$ from each station, we measured coda $Q$ for frequency bands of $1-2,2-4,4-8,8-16$, and $16-32 \mathrm{~Hz}$, respectively. Then coda $Q$ maps are constructed with average station spacing of $20 \mathrm{~km}$ over Japan, except the Hokkaido Island. The most striking feature of the obtained maps is the significant spatial variation within Japan, up to a factor of 3 for the lower frequency bands, as well as its strong frequency dependence. Such high spatial resolution was not possible to achieve without the high density and sensitivity of the Hi-net. We found several low coda $Q$ regions for frequency band of 1-2 Hz including the southwestern Shikoku, eastern Shimane-western Tottori along the Japan Sea coast and the disjointed spots along the Pacific coast from the Kanto-Tokai region to southern edge of the Kii-peninsula. However, the most conspicuous low coda $Q$ zone is a narrow belt from Niigata towards south-west to the Biwa lake along the Japan Sea coast. This low $Q$ zone appears at frequency bands of both 1-2 and 2-4 Hz, and it coincides with the zone of high deformation rate revealed from the GPS data. For frequency bands $4-16 \mathrm{~Hz}(2-4$ $\mathrm{Hz}$ in Kyushu), the low coda $Q$ areas agree with volcanic and geothermal areas. For frequency band of 16-32 Hz, the coda $Q$ is distributed nearly uniformly throughout the study area.
\end{abstract}

Key words: Hi-net, coda $Q$, brittle zone, ductile zone.

\section{Introduction}

Coda waves of local earthquakes have been studied extensively since Aki (1969), and the properties of coda waves were summarized by Sato and Fehler (1998) in a systematic mannered book. Coda wave record is usually represented by the time-dependent power spectrum $P(\omega \mid t)$. The first attempt to predict the explicit form of $P(\omega \mid t)$ was made by Aki and Chouet (1975) assuming that coda waves are singly back-scattered $S$ waves. They obtained the following formula for a station collocated as the earthquake source.

$$
P(\omega \mid t)=\frac{2 g(\pi)|S(\omega)|^{2}}{\beta t^{2}} \exp \left(-\omega t / Q_{c}\right)
$$

where $\omega$ is the angular frequency, $t$ is time measured from the original time of the earthquake, $S(\omega)$ is the source spectrum, $\beta$ is $S$-wave velocity, $g(\pi)$ is back scattering coefficient, and $Q_{c}$, called "coda $Q$ ", is the measure of the energy loss suffered by the scattered waves. The details of the derivation of Eq. (1) is described by Aki (1981) as well as by Sato and Fehler (1998) in slightly different terms.

What the coda $Q$ means precisely is still controversial, partly because there are several plausible answers to the question. Within the context of the single backscattering model, coda $Q$ appears to present an effective attenuation

\footnotetext{
*Also at Observatoire Volcanologique de Piton de la Fournaise of the Institut de Physique du Globe, Paris.

Copy right(c) The Society of Geomagnetism and Earth, Planetary and Space Sciences (SGEPSS); The Seismological Society of Japan; The Volcanological Society of Japan; The Geodetic Society of Japan; The Japanese Society for Planetary Sciences; TERRAPUB
}

including both absorption and scattering loss. This idea was supported by the close agreement between coda $Q$ and S-wave $Q$ observed in the Kanto region by Aki (1980). More recently, Sarker and Abers (1998) compared the coda $Q$ with $\mathrm{S}$-wave $Q$ measured using seismograms recorded at two seismic arrays in Caucasus and Kopet Dagh (Turkmenistan), Their results demonstrated that coda $Q$ agrees with S-wave $Q$ in both areas. Jannaud et al. (1991) confirmed the validity of Eq. (1) numerically.

On the other hand, based on an energy-flux model, Frankel and Wennerberg (1987) suggested that coda $Q$ is intrinsic loss. Gusev (1995) demonstrated that the coda decay may be quantitatively explained if the scattering coefficient decreases with depth that causes the leakage of scattering energy to the bottom and such loss cannot be discriminated from the intrinsic loss. Applying the radiative transfer theory $\mathrm{Wu}$ (1985) proposed a method to estimate the relative contribution of scattering and intrinsic loss to the total attenuation. Wu's method was improved later to the "Multiple Lapse Time Window Analysis" by Felher et al. (1992). This method was applied to data in Japan (Felher et al., 1992; Hoshiba, 1993), Hawaii (Mayeda et al., 1992) and California (Mayeda et al., 1992; Jin et al., 1994). Jin et al. (1994) compared the observed coda $Q$ with the intrinsic, scattering and total $Q$ in each area and found that coda $Q$ is bounded between the total $Q$ and intrinsic $Q$, empirically. The relative contribution of the scattering attenuation and intrinsic absorption varies from region to region and also depends on frequency. It is necessary to take into account the depth dependence of total scattering coefficient and intrinsic absorption in addition to seismic velocity for a more 


\section{Amplitude Response of Hi-net Station}
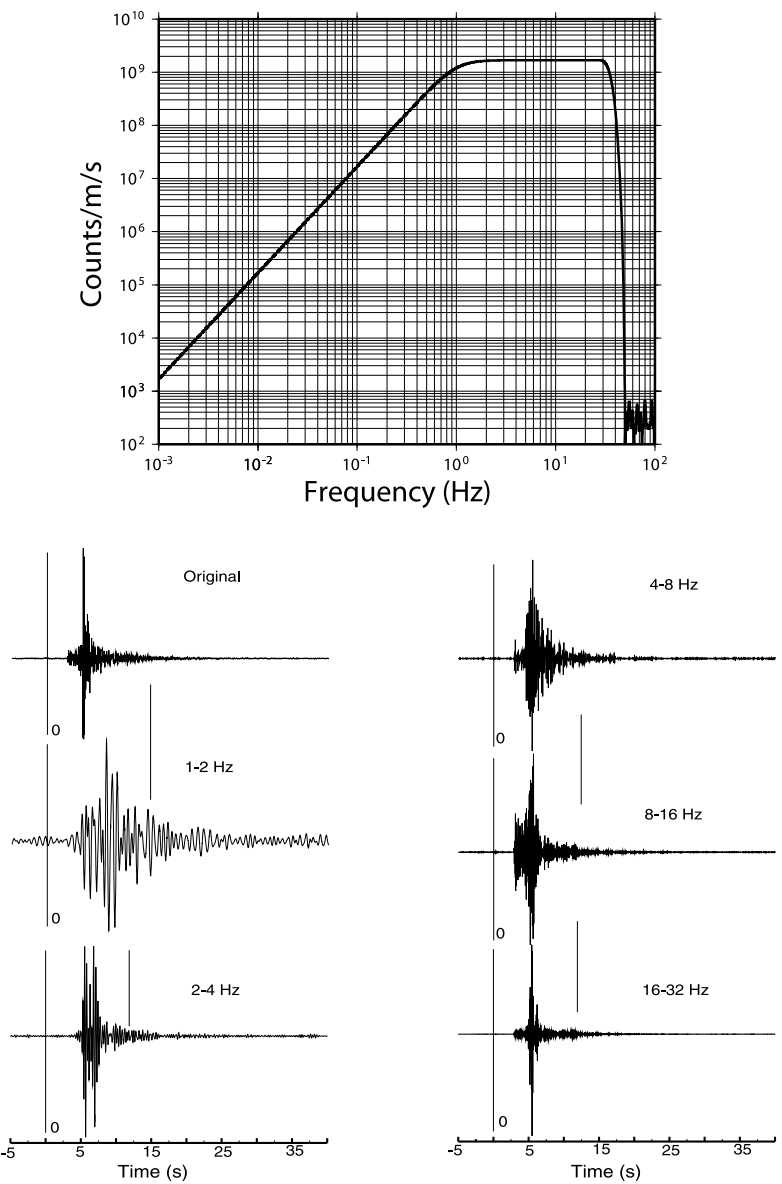

Fig. 1. The overall frequency response of the Hi-net system (top) and a representative original seismogram and its corresponding octave seismograms (bottom). The station is in Kyushu, and earthquake is about $10 \mathrm{~km}$ away. The thin vertical lines indicate the starting time of coda that is slightly different for each octave seismograms due to the phase shift for different frequency bands. And the ending time of coda is 30 second in lapse time or the signal-to-noise ratio $=2$, whichever comes first.

complete understanding of coda $Q$.

Nevertheless, coda $Q$ is an interesting geophysical parameter that show strong correlation with seismicity in both space (e.g., Jin and Aki, 1988) and time (e.g., Jin and Aki, 1989). Results from numerous studies on coda $Q$ over the last two decades (e.g. Singh and Herrmann, 1983; Hoshiba, 1993; Mitchell et al., 1997; Baqer and Mitchell, 1998) show that coda $Q$ varies systematically with the tectonic activity by more than an order of magnitude as summarized by Sato and Fehler (1998) and by Mitchell and Cong (1998). However, the spatial resolution of the coda $Q$ maps from earlier studies was low because of the large station spacing as well as the use of relatively distant earthquakes. The Hi-net, established and operated by NIED, nearly uniformly distributed over Japan with a station spacing of $20 \mathrm{~km}$ with the high local seismicity, offers an opportunity to study spatial distribution of coda $Q$ with unprecedented high resolution.

\section{Data and Method}

The Hi-net started to offer its uniform and stable waveform data from the end of 2000 for Kyushu, Shikoku, and Honshu in Japan. In this study we use seismograms recorded at 582 Hi-net stations over Japan, except the Hokkaido Island, for earthquakes occurring from January 2001 through July 2004. For each Hi-net station we search for earthquakes with magnitude 1.5-3.0 located within 30 $\mathrm{km}$ from the station with focal depth 5-30 km. Thus, we can have sufficient coda length with the high $\mathrm{S} / \mathrm{N}$ ratio to estimate coda $Q$ by restricting the lapse time within 30 sec. According to the single backscattering model, $30 \mathrm{sec}$ lapse time corresponds to the farthest scatterers being located within $45 \mathrm{~km}$ from the station (See a confirmation of this rule for southern California in Aki, 1996). We were able to find 10 to 20 earthquakes meeting the above requirements for each station. Each original seismogram was band-pass filtered to 5 frequency bands: $1-2,2-4,4-8,8$ 16 and $16-32 \mathrm{~Hz}$. A 5-second moving lapse time window, overlapping with the neighbours by 2.5 second, was applied to calculate $P(f \mid t)$, then coda $Q$ is calculated by fitting Eq. (1) for each frequency band and averaged over 3 components. For each station, we averaged coda $Q$ over earthquakes for each frequency band. Totally, about 20,000 original seismograms were analyzed. Figure 1 shows the overall frequency-response of the Hi-net system and a representative original and band-pass filtered seismograms recorded at station MISH, Kyushu for an M2.1 earthquake about 10 $\mathrm{km}$ away. The frequency dependence of coda $Q$ is represented by the power law parameter, calculated by fitting the relationship of $Q(f)=Q_{0} f^{\gamma}$ for each station, where $Q_{0}$ is coda $Q$ at $f=1 \mathrm{~Hz}$.

\section{Results}

The coda $Q$ measured at $582 \mathrm{Hi}$-net stations by the procedure described above are smoothed at 0.1 degree square in latitude and longitude and mapped using GMT (Wessel and Smith, 2001) as shown in Fig. 2(a)-(e) for frequency bands of $1-2,2-4,4-8,8-16$, and $16-32 \mathrm{~Hz}$, respectively. Figure 2(f) shows a map for $\gamma$; the parameter of frequency dependence of coda $Q$. The most surprising feature of Fig. 2 is the large spatial variation of coda $Q$ within Japan for the lower frequency bands as well as its frequency dependence. Hoshiba (1993) measured coda $Q$ for frequency bands of $1-2,2-4$, and $4-8 \mathrm{~Hz}$ at $16 \mathrm{JMA}$ stations over Japan. However, the spatial variations were smooth partially because of the use of long lapse-time window and partially because of the sparseness of stations. The high-resolution coda $Q$ map shown in Fig. 2 could never be constructed without benefits of the high density and high sensitivity of the Hi-net stations.

\subsection{The low coda $Q$ regions at lower frequency bands}

(1) The southwestern Shikoku Island and the disjoined small areas along the Pacific coast from the Kanto-Tokai region to southern edge of the Kii-peninsula show low coda $Q$, corresponding to the epicentral area of great earthquakes caused by the subduction of the Philippine Sea plate. It is interesting to note that the low $Q$ is significant only for frequency band of $1-2 \mathrm{~Hz}$, suggesting relatively larger size of the scatterers in the area.

(2) The Shimane-Tottori area shows low coda $Q$ at frequency band of $1-2 \mathrm{~Hz}$ and relatively high $Q$ for frequencies higher than $4 \mathrm{~Hz}$ resulting in very strong frequency de- 

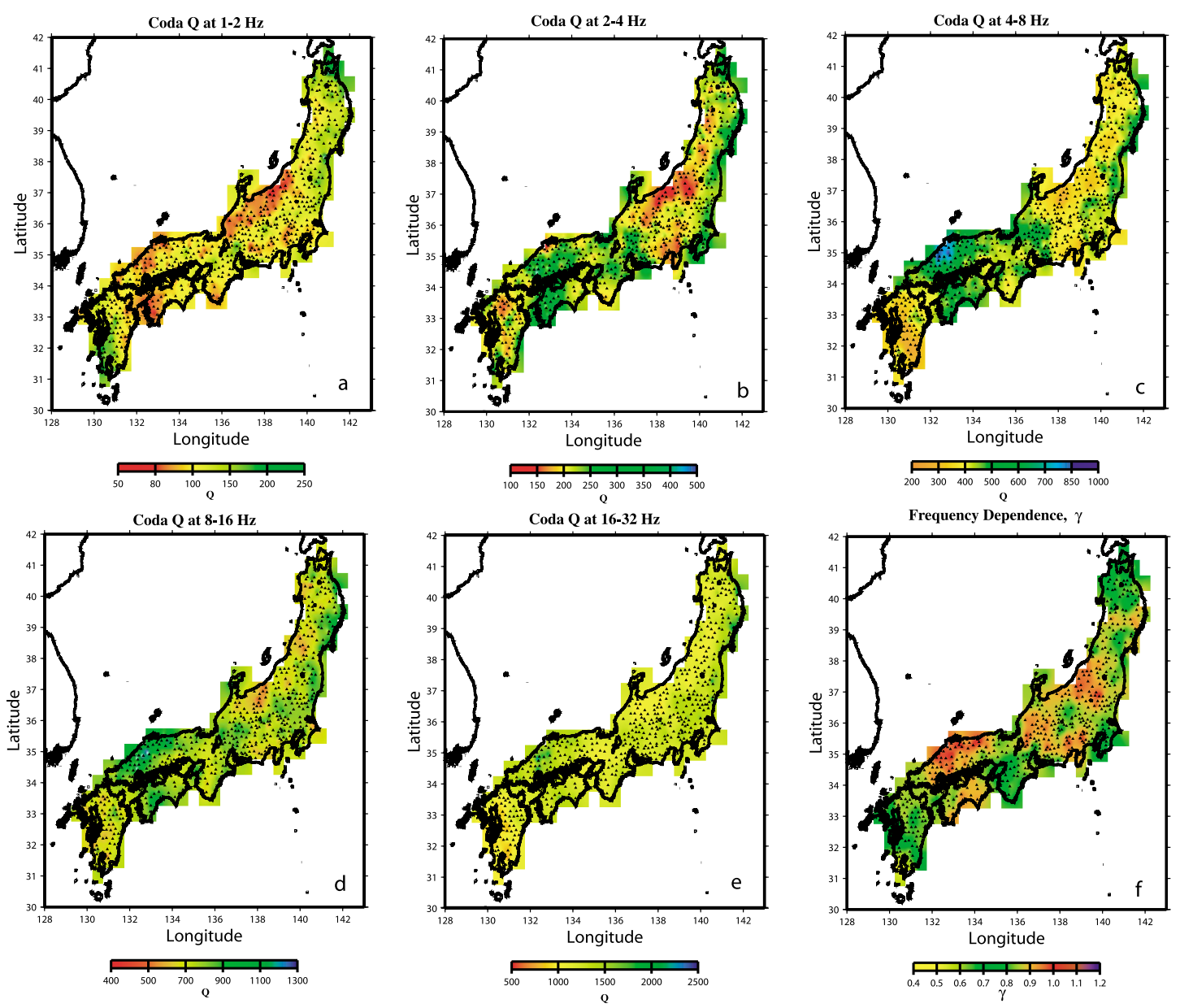

Fig. 2. Spatial distribution of coda $Q$ for the 5 octave frequency bands (a)-(e) and its frequency dependence (f). The scale of $Q$ value is shown in the bottom of each sub-figure. The locations of the areas mentioned in the text are indexed in Fig. 3.

pendence. As well known, an Mw 6.6 earthquake occurred in 2000 in this area.

(3) The most conspicuous low coda $Q$ region is found for a narrow zone from Niigata to the Biwa Lake along the Japan Sea coast. This low coda $Q$ zone is significant for frequency bands of $1-2$, and $2-4 \mathrm{~Hz}$. This low $Q$ zone fits remarkably well with the zone of concentrated deformation revealed from GPS data observed during June 1996 to May 2000 (Sagiya et al., 2000). The Mw 6.8 Niigata earthquake occurred in the low coda $Q$ zone in 2004, a month after we recognized the coincidence of the zone with the concentrated deformation zone.

For frequencies higher than $4 \mathrm{~Hz}$ the low $Q$ zone appears shifted toward the north and connecting with the low $Q$ areas corresponding to the volcano chain in the western Tohoku region of Japan. This is consistent with Matsumoto and Hasegawa (1989).

3.2 The low coda $Q$ regions for higher frequency bands

(1) From north to south along the central Kyushu Island, the low coda $Q$ zone is significant at frequencies $2-4$ and 4-8 Hz. This low coda $Q$ zone coincides with the areas of active volcanoes.

(2) The Suruga Bay area along the Pacific coast shows significant low coda $Q$ area at frequency 2-4 Hz.

(3) The low coda $Q$ zone along the Tohoku volcano chain appears as small spots for frequency $2-4 \mathrm{~Hz}$ and becomes

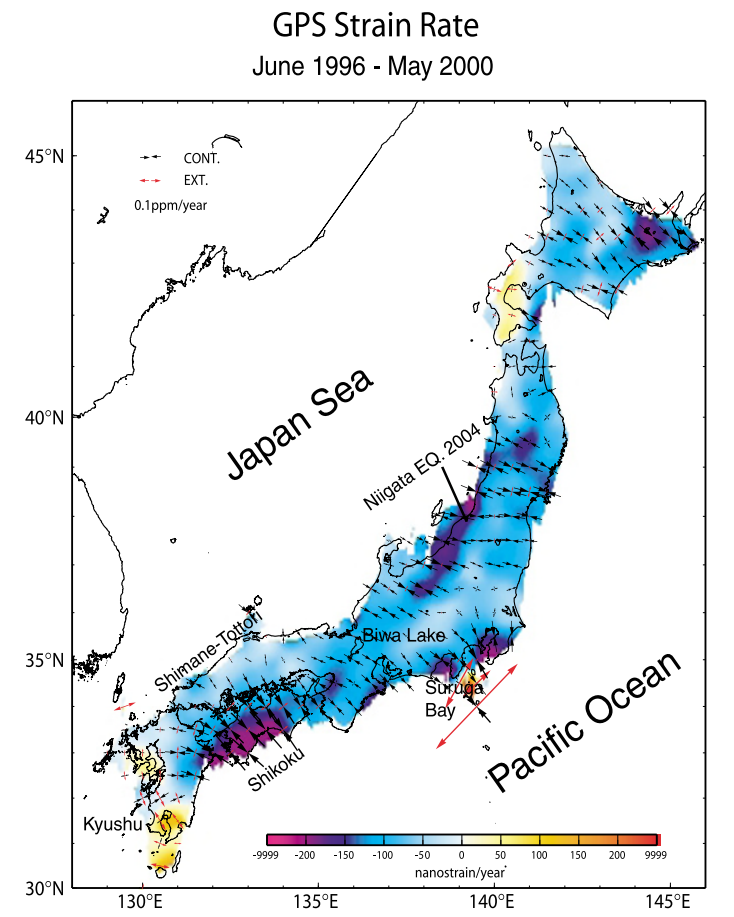

Fig. 3. Spatial distribution of the strain rate revealed from the data observed by the GEONET during June 1996 to May 2000 (following Sagiya et al., 2000). 
most significant for $4-8 \mathrm{~Hz}$, then turns back to small spots for $8-16 \mathrm{~Hz}$.

For frequency band $16-32 \mathrm{~Hz}$, as shown in Fig. 2(e), the coda $Q$ distribution is nearly uniform over the study region indicating that the uniform distribution of smaller scale scatterer over the study region. However, the active volcano regions in Kyushu and NE Japan still have relatively low coda $Q$. And the coda $Q$ along the Japan Sea coast reminds to be lower relative to that along the Pacific Ocean coast as revealed by Matsumoto and Hasegawa (1989).

\section{The Concentrated Deformation Zone (NKTZ) with low coda $Q$}

Sagiya et al. (2000) discovered several regions of significantly high strain rate in Japan, as shown in Fig. 3, where the strain rate was calculated using ground velocity observed by the GPS network (GEONET) during the period from June 1996 to May 2000.

Comparing Fig. 3 with 2(a) and 2(b), we find that all the high strain rate regions (except the one in the Hokkaido Island) are coincident with the low coda $Q$ regions, the western Shikoku, the Kanto-Tokai along the Pacific coast, and the Niigata to Biwa-lake low $Q$ zone. The last one is particularly interesting to us because it is a region of large intraplate earthquakes, including the M6.8 earthquake $(138.87 \mathrm{E}, 37.29 \mathrm{~N}, h=13 \mathrm{~km})$ occurred in the central Niigata region, at Oct. 23, 2005, shortly after this coda $Q$ map has been constructed. We shall focus our discussion on this zone of low coda $Q$ and high strain rate.

The high strain rate zone along the Japan Sea coast has been named as Niigata-Kobe Tectonic Zone (NKTZ) by Sagiya et al. (2000). The observed difference in deformation rates between the NKTZ and its surrounding is almost one order of magnitude (Sagiya et al., 2000). To produce such a significant difference in deformation rate requires a strong stress concentration in the NKTZ unless there is strong regional variation on the stiffness/viscosity in the region. Among various models proposed by Shimazaki and Zhao (2000), Mazzotti et al. (2000), Miyazaki and Heki (2001), and Iio et al. (2002, 2004), we are particularly interested in the last one, who attributed the concentrated deformation to the low viscosity in weak zone(s) existing in the lower crust of the lithosphere.

Zoback and Zoback (2002) offered a new perspective on the role of ductile part of the lithosphere during the earthquakes loading processes by plate-driving forces from a global study of tectonic stress. Assuming that the lithosphere consisting of 3 layers; the brittle upper crust, the ductile lower crust, and the upper mantle, supports platedriving forces as a whole, they conclude that because of the applied forces to the lithosphere would result in steadystate creep in the lower crust and upper mantle, as long as the three-layer lithosphere is coupled, stress will build up in the brittle upper crust due to the creep deformation in the layer below. Hence, the tectonically stable region is stable because of the low deformation rate in the ductile part and the active region is active because of the high deformation rate in the ductile part. This model is similar to that of Iio et al. $(2002,2004)$ in supporting the idea of which viscosities in the ductile zone control the intraplate deformation in the overlying brittle part. But there is an important difference between them; the former is in the domain of global spatial scale and geological time scale, while the latter is in that of regional spatial scale and time scale of years to decades. Obviously the latter is more relevant to the issue of earthquake prediction.

Jin and Aki $(1989,1993)$ studied the temporal and spatial correlation between coda $Q^{-1}$ and seismicity in both southern and central California. They defined the frequency of earthquakes in a specified magnitude range around $M_{c}$ relative to the total frequency as $N\left(M_{c}\right)$ (in \%) and found a remarkable positive correlation between the temporal variation of $Q_{c}^{-1}$ and $N\left(M_{c}\right)$ for over 50 years in both regions. The correlation coefficient reached its peak (around 0.8) at the zero time shift for a choice of $M_{c}$ 3-3.5 for southern California and 4-4.5 for central California. To explain this observation, Jin and Aki $(1989,1993)$ proposed the "creep model" in which the ductile fractures in the brittleductile transition zone of lithosphere have a characteristic size comparable with the source dimension of an earthquake with magnitude $M_{c}$ (a few hundred meters for southern California and roughly a $\mathrm{km}$ for central California). Under the loading of the plate-driving forces, the increase in the density of ductile fractures increases the coda $Q^{-1}$ and, at the same time, generates stress concentration with the same scale length as the size of the ductile fracture responsible for the increase in relative frequency of earthquakes with magnitude around $M_{c}$. This model agrees with Iio et al. (2004) but requires much smaller characteristic scale length of fractures in the lower crust weak zone than envisioned by them. As pointed out by Iio et al. (2002), the high ${ }^{3} \mathrm{He} /{ }^{4} \mathrm{He}$ ratio and high conductivity observed in the NKTZ suggests that the brittle-ductile transition zone in the NKTZ is weakened by fluid (water) from the upper mantle, the fractures in the ductile zone could be the fluid container. And the strong frequency dependency of coda $Q$ shown in Fig. 2(f) indicates that the fractures indeed have a characteristic size. Benites (1990) found by numerical simulations that $Q_{c}^{-1}$ has a peak at $k d=2$, where $k$ is the wave-number and $d$ is the length of a crack assumed as the scatterer. In the case of NKTZ, the peak of $Q_{c}^{-1}$ appears in the frequency band of $1-4 \mathrm{~Hz}$, corresponding scatterer's size in the range from a few hundred meters to a $\mathrm{km}$ for the $S$-to- $S$ scattering.

\section{The Spatial Distribution of $N\left(M_{c}\right)$}

Recently, Aki (2004) noticed that the simultaneous positive correlation between $Q_{c}^{-1}$ and $N\left(M_{c}\right)$ obtained for the 50 year-period by Jin and Aki $(1989,1993)$ for California, was disturbed for several years before the 1952 M7.5 earthquake, Kern County, California and the 1989 M7.1 earthquake, Loma Prieta, California. Jin et al. (2004) extended the analyses of temporal variation of coda $Q^{-1}$ and $N\left(M_{c}\right)$ for central and southern California and applied a 10 year moving time window to calculate the cross-correlation between $Q_{c}^{-1}$ and $N\left(M_{c}\right)$. They found that the simultaneous correlation was disturbed before all major earthquakes ( $M \geq 7$ ) occurred in the study region. The disturbance is, consistently, a delay in the fluctuation of coda $Q^{-1}$ relative to that of $N\left(M_{c}\right)$ before the occurrence of a major earthquake. According to the "brittle-ductile interaction hy- 

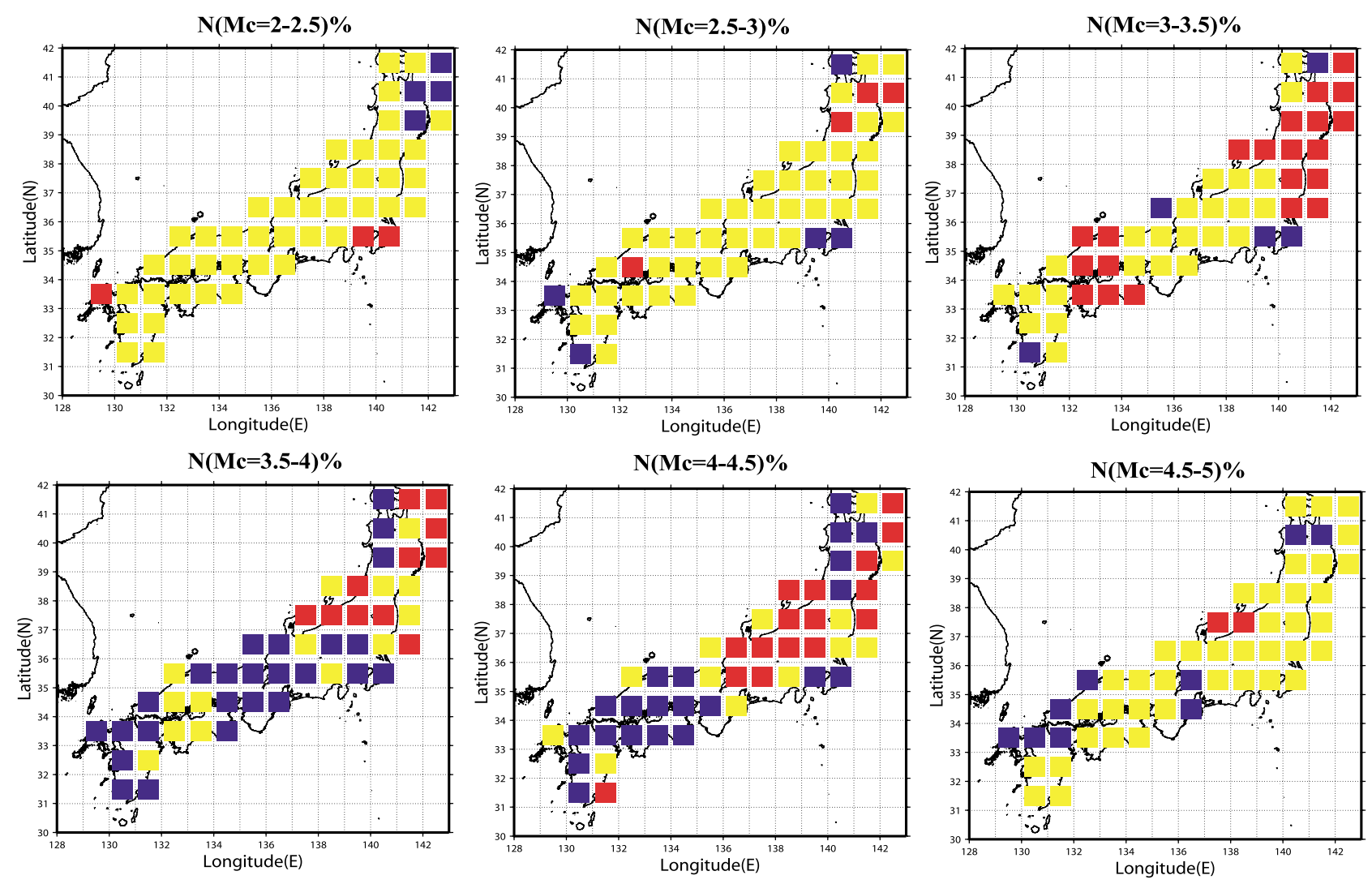

Fig. 4. Distribution of $N\left(M_{c}\right) \% . N\left(M_{c}\right) \%$ is the relative frequency of earthquakes magnitude $\left(M_{c}\right)$ in a certain range as shown in the top of each sub-figure and it is calculated for $1^{\circ}$ square and smooth with $0.5^{\circ}$. The red, blue, and yellow represent where the $N\left(M_{c}\right) \%$ is larger than, smaller than or equal to the (average \pm 1 standard error).

pothesis" of earthquake loading processes by plate-driving forces proposed by Aki (2004), the coda $Q^{-1}$ represents the density of the fractures in the ductile part of lithosphere, and $N\left(M_{c}\right)$ represents the response of the brittle part to the stress induced by the ductile fracture. In the normal loading process the interaction between the ductile and brittle parts of the lithosphere is harmonic leading to the simultaneous positive correlation between coda $Q^{-1}$ and $N\left(M_{c}\right)$. This harmony may be disturbed because of the effect of the change in the material property of the brittle part in the anomalous period before a major earthquake on the loading process. Unlike the loading machine in a laboratory, the loading of plate driving forces is an internal process and may be affected by the change in the material property. Since the change in the brittle part is the cause for the anomalous period, the change in $N\left(M_{c}\right)$ must precede that of coda $Q^{-1}$. We can also simply imagine that the strain energy stored in the brittle part of lithosphere reaching a saturation limit and starting to flow back to the ductile part, thus $N\left(M_{c}\right)$, that expresses an event in the brittle part, preceding coda $Q^{-1}$, that expresses an event in the ductile part.

Central to the above brittle-ductile interaction hypothesis is the assumption that $M_{c}$ characteristic to a seismic region is originated from a characteristic size of fractures in the ductile zone of the lithosphere. However, we are not able to study the temporal change of coda $Q$ in Japan using Hi-net data due its short history. To test this idea for Japan, we compare the spatial variation of coda $Q$ to that of $N\left(M_{c}\right)$ for the period for which the coda $Q$ maps is constructed.
We use JMA catalog for earthquakes with $M \geq 2.0$ occurred during January 2001 to July 2004 in the study region with focal depth less than $40 \mathrm{~km}$. For each Longitude $\left(E_{i}\right)$ and Latitude $\left(N_{i}\right)$ node, we count the earthquakes occurred within the grid of $\left(E_{i} \pm 1^{\circ} ; N_{i} \pm 1^{\circ}\right)$ with magnitude ranges of 2-2.5, 2.5-3.0, 3.0-3.5, 3.5-4.0, 4.0-4.5, and 4.5-5.0, respectively. The increment of $\left(E_{i}, N_{i}\right)$ is $1^{\circ}$ from $\left(128.5^{\circ}\right.$; $\left.29.5^{\circ}\right)$ to $\left(143.5^{\circ} ; 42.5^{\circ}\right)$ and overlaped with the neighbours by $0.5^{\circ}$. The percentage of earthquakes in each magnitude range within each grid is plotted at $\left(E_{i}, N_{i}\right)$ as shown in Fig. 4. For each $M_{c}$ we calculate the average $N$ over the whole region as $\bar{N}\left(M_{c}\right)$ with standard error $\sigma$. The red, blue, and yellow indicate where the calculated $N\left(M_{c}\right)$ is larger than $\left[\bar{N}\left(M_{c}\right)+\sigma\right]$, smaller than $\left[\bar{N}\left(M_{c}\right)-\sigma\right]$, and within $\left[\bar{N}\left(M_{c}\right) \pm \sigma\right]$, respectively. The spatial variation of $N\left(M_{c}\right)$ for $M_{c}$ ranges 2-2.5 and 2.5-3 are very small, less than $20 \%$, and it jumps suddenly to a factor of 3 for $M_{c}>3$. Since the jump is abrupt and the variability is similar for all magnitude ranges greater than 3.0, such a jump in variability may not be attributed to the smaller sample size. We believe that this jump is real, and corresponds to a similar jump in variability found for the coda $Q$ map when the frequency at which coda $Q$ was measured crossed 4-8 Hz. Coda $Q$ maps showed a large spatial variation for frequencies lower than 4-8 Hz, while those for higher frequencies suddenly become uniform throughout Japan. This observation is consistent with the brittle-ductile interaction hypothesis in which the dominant frequency at which coda $Q$ change occurs should be inversely related to $M_{c}$. 

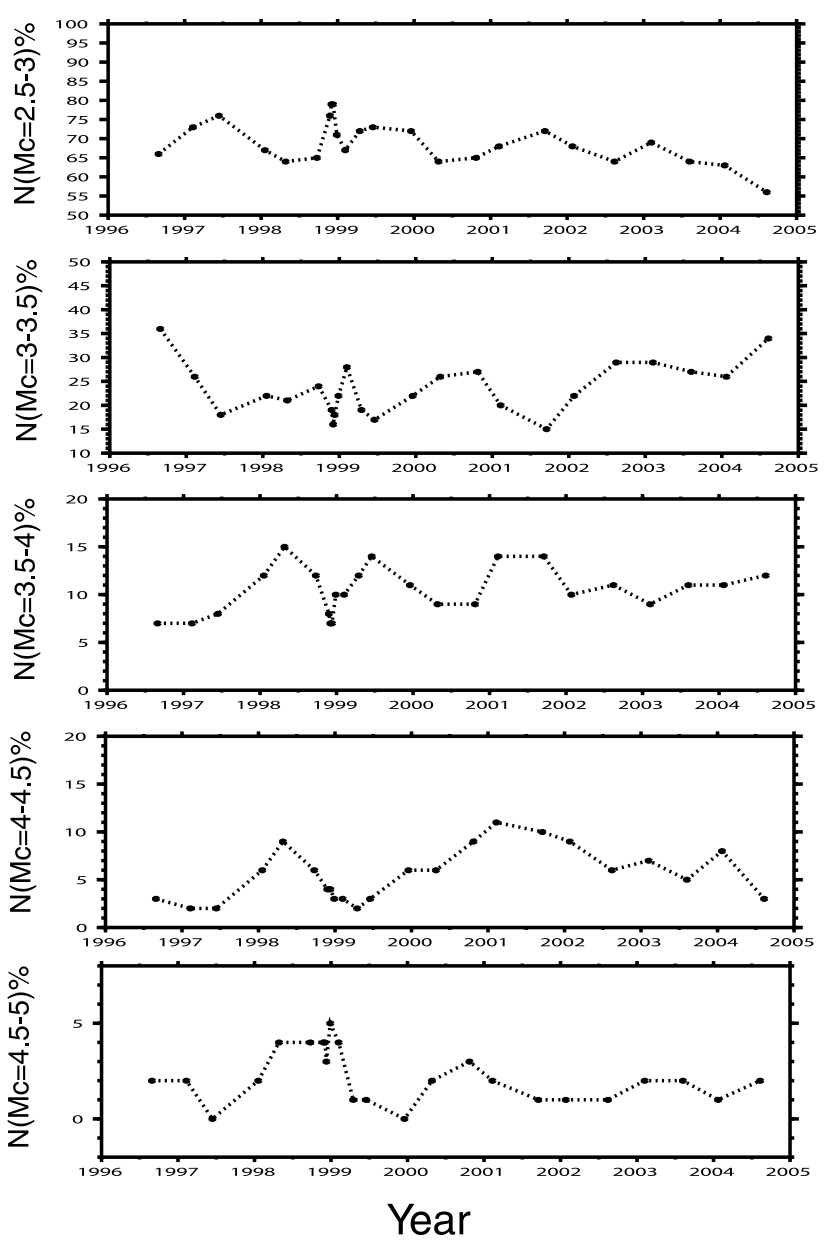

Fig. 5. The temporal change of $N\left(M_{c}\right) \%$ with different $M_{c}$ in the hypocentral area of the 2004 Mid Niigata M6.8 earthquake.

The red colored grid in Fig. 4 represents $N\left(M_{c}\right)$ higher than the mean by more than one standard error, and the blue represents $N\left(M_{c}\right)$ lower than the mean by more than one standard error. The yellow represents $N\left(M_{c}\right)$ within one standard error from the mean. Comparing Fig. 4 with Fig. 2, we can find some anomalously low coda $Q$ area which also shows an anomalously high $N\left(M_{c}\right)$. For example, the low coda $Q$ area in southwestern Shikoku and ShimaneTottori area corresponds to the high $N\left(M_{c}\right)$ for $M_{c} 3$ to 3.5. In the context of the brittle-ductile interaction hypothesis, this indicates that the ductile fracture size under the area is several hundred meters. The coda $Q$ measured for the same time period is low indicating that the coda $Q^{-1}$ and $N\left(M_{c}=3-3.5\right)$ is currently coincident. Of course, a snap shot of coda $Q$ and $N\left(M_{c}\right)$ maps cannot tell if it is in the normal or abnormal period.

Here we present a very limited observation related to the NKTZ region. The JMA catalog with uniform magnitude determination goes back to 1995 for the NKTZ region. Figure 5 plots the temporal variation of $N\left(M_{c}\right)$ for $M_{c}$ ranges of $2.5-3,3-3.5,3.5-4$, and $4-4.5$, from the top to the bottom, respectively, for earthquakes occurred in the region $150 \mathrm{~km}$ around the epicenter of the M6.8 central Niigata earthquake. $N\left(M_{c}\right)$ for $M_{c}=3-3.5$ appears to increase from the late 2002 while $N\left(M_{c}=4-4.5\right)$ decreases at the same time. If $M_{c}$ applicable to the Niigata area is 4-4.5, this observation combined with the low coda $Q$ shown in Fig. 2 implies an anomalous period for the Niigata area in the context of the brittle-ductile interaction hypothesis. Obviously we need to accumulate more data on coda $Q$ and $N\left(M_{c}\right)$, specially, for its temporal variations.

\section{Conclusion Remarks}

(1) We constructed high spatial resolution coda $Q$ maps of Japan using the Hi-net data for frequency bands of 1-2, 2-4, 4-8, 8-16, and 16-32 Hz. In general, the low coda $Q$ regions in the lower frequencies are correlated with high seismic areas of both subduction and the intraplate earthquakes, and the low coda $Q$ areas for the higher frequencies are correlated with the areas of quaternary volcanoes.

(2) We gave special attention to the spatial coincidence between the zone of low coda $Q$ in $1-2$ and $2-4 \mathrm{~Hz}$ bands with the high strain rate zone called NKTZ found from the GPS data. This is consistent with the brittle-ductile interaction hypothesis of earthquake loading by plate-driving forces proposed by Aki (2004) on the basis of three independent studies; global study of tectonic stress by Zoback and Zoback (2002), regional study of Iio et al. (2002, 2004), and the observed correlation between coda $Q$ and $N\left(M_{c}\right)$ by Jin and Aki $(1989,1993)$. The occurrence of the Mw 6.8 central Niigata earthquake within the NKTZ in 2004 encourages further studies along this line.

(3) Modeling and monitoring the earthquake loading process in a seismic region is essential for earthquake prediction. Modeling the loading process is, however, not a simple task because the individual earthquake is not an isolated system and a variety of interactions among the model elements exist in a broad area. At each stage of the development of loading process, we expect numerous possible scenarios for the future course. Therefore, we need models that could be effectively constrained and adjusted by as many as available monitored data. The brittle-ductile interaction hypothesis is only one of them. We need many such models that can be constrained and adjusted by a variety of observations for a reliable earthquake prediction.

Acknowledgments. This work was not possible without the Hinet data. We are grateful to those who made continuous efforts to develop and maintain the Hi-net system and its database. Special thanks are due to Prof. T. Sagiya of Nagoya University for offering the strain rate map and constructive suggestions. Our appreciation also goes to Dr. K. Obara of NIED not only for his excellent work as the chief of the Hi-net but also for his encouragement and suggestions in processing the huge data set used in the present study. The constructive suggestions form the 2 anonymous referees are deeply appreciated. All the figures are made using the GMT software by Wessel and Smith (2001).

\section{References}

Aki, K., Analysis of seismic coda of local earthquakes as scattering waves, J. Geophys. Res., 74, 615-631, 1969.

Aki, K., Attenuation of shear waves in the lithosphere for frequencies from 0.05 to $25 \mathrm{~Hz}$, Phys. Earth Planet. Inter., 21, 50-60, 1980.

Aki, K., Attenuation and scattering of short-period seismic waves in the lithosphere, in Identification of Seismic Sources-Earthquake or Underground Explosion, edited by E. S. Husebye and S. Mykkeltveit, pp. 515541, D. Reidel, Dordrecht, Holland, 1981.

Aki, K., Scale dependence in earthquake phenomena and its relevance to earthquake prediction, Proc. Natl. Acad. Sci., USA, 93, 3740-3747, 1996. 
Aki, K., A new view of earthquake and volcano precursors, Earth Planets Space, 56, 689-714, 2004.

Aki, K. and B. Chouet, Origin of coda waves: Source, attenuation and scattering effects, J. Geophys. Res., 80, 3322-3342, 1975.

Baqer, S. and J. Mitchell, Regional variation of $\operatorname{Lg}$ coda $Q$ in the continental United States and its relation to crustal structure and evolution, PAGEOPH, 153, 613-636, 1998.

Benits, R., Seismological applications of boundary integral and Gaussian beam methods, PhD thesis, MIT, Massachusetts, 1990.

Felher, M., M. Hoshiba, H. Sato, and K. Obara, Separation of scattering and intrinsic attenuation for the Kanto-Tokai region, Japan, using measurements of S-wave energy versus hypocentral distance, Geophys. $J$. Int., 108, 787-800, 1992.

Frankel, A. and L. Wennerberg, Energy-flux model of seismic coda: Separation of scattering and intrinsic attenuation, Bull. Seismol. Soc. Am., 77, 1223-1251, 1987.

Gusev, G. G., Vertical profile of turbidity and coda $Q$, Geophys. J. Int., 123, 665-672, 1995.

Hoshiba, M., Separation of scattering attenuation and intrinsic absorption in Japan with the multiple lapse time window analysis from full seismogram envelope, J. Geophys. Res., 98, 15,809-15,824, 1993.

Iio, Y., T. Sagiya, Y. Kobayashi, and I. Shiozaki, Water-weakened lower crust and its role in the concentrated deformation in the Japanese Islands, Earth Planet. Sci. Lett., 203, 245-253, 2002.

Iio, S., T. Sagiya, and Y. Kobayashi, Origin of the concentrated deformation zone in the Japanese Islands and stress accumulation process of intraplate earthquakes, Earth Planets Space, 56, 831-842, 2004.

Jannaud, L. R., P. M. Adler, and C. G. Jacqin, Spectral analysis and inversion of codas, J. Geophys. Res., 96, 18,215-18,231, 1991.

Jin, A. and K. Aki, Spatial and temporal correlation between coda $Q$ and seismicity in China, Bull. Seismol. Soc. Am., 78, 741-769, 1988.

Jin, A. and K. Aki, Spatial and temporal correlation between coda $Q^{-1}$ and seismicity and its physical mechanism, J. Geophys. Res., 94, 14,04114,059, 1989.

Jin, A. and K. Aki, Temporal correlation between coda $Q^{-1}$ and seismicity-Evidence for a structure unit in the brittle-ductile transition zone, J. Geodynamics, 17, 95-120, 1993.

Jin, A., K. Mayada, D. Adams, and K. Aki, Separation of intrinsic and scattering attenuation in southern California using TERRAscope data, J. Geophys. Res., 99, 17,835-17,848, 1994.

Jin, A., K. Aki, Z. Liu, and V. I. Keilis-Borok, Seismological evidence for the brittle-ductile interaction hypothesis on earthquake loading, Earth Planets Space, 56, 823-830, 2004.

Matsumoto, S. and A. Hasegawa, Two-dimensional coda $Q$ structure beneath Tohoku, NE Japan, Geophys. J. Int., 99, 101-108, 1989.

Mayeda, K., K. S. Koyanagi, and K. Aki, A comparative study of scattering, intrinsic and coda $Q^{-1}$ for Hawaii, Long Valley and central California between 1.5 and 15.0 Hz, J. Geophys. Res., 97, 6643-6659, 1992.

Mazzotti, S. X., L. Pichon, and P. Henry, Full interseismic locking of the Nankai and Japan-west Kurile subduction zones: An analysis of uniform elastic strain accumulation in Japan constrained by permanet GPS, $J$. Geophys. Res., 105, 13,159-13,177, 2000.

Mitchell, B. J. and L. Cong, $\operatorname{Lg}$ coda $Q$ and its relation to the structure and evolution of continents: A global prespective, PAGEOPH, 153, 655$663,1998$.

Mitchell, B. J., Y. Pan, J. Xie, and L. Cong, Lg coda $Q$ variation across Eurasia and its relation to crustal evolution, J. Geophys. Res., 102, 22,767-22,780, 1997.

Miyazaki, S. and K. Heki, Crustal velocity field of southwest Japan: Subduction and arc-arc collision, J. Geophys. Res., 106, 4305-4326, 2001.

Sagiya, T., S. Miyazaki, and T. Tada, Continuous GPS array and presentday crustal deformation of Japan, PAGEOPH, 157, 2003-2322, 2000.

Sarker, G. and G. A. Abers, Comparison of seismic body wave and coda wave measure of $Q, P A G E O P H, \mathbf{1 5 3}, 665-684,1998$.

Sato, H. and M. C. Fehler, Seismic Wave Propagation and Scattering in the Heterogeneous Earth, Springer-Verlag, New York, 308 pp., 1998.

Shimazaki, K. and Y. Zhao, Dislocation model for strain accumulation in a plate collision zone, Earth Planets Space, 52, 1091-1094, 2000.

Singh, S. K. and R. B. Herrmann, Regionalization of crustal coda $Q$ in the continental United States, J. Geophys. Res., 88, 527-538, 1983.

Wessel, P. and W. H. F. Smith, The Generic Mapping Tools, version 3.4 released, http://gmt.soest.hawaii.edu, 2001.

Wu, R.-S., Multiple scattering and energy transfer of seismic wavesSeparation of scattering effect from intrinsic attenuation-1. Theoretical modeling, Geophys. J. R. Astron. Soc., 82, 57-80, 1985.

Zoback, M. D. and M. L. Zoback, State of stress in the Earth's lithosphere, International Handbook of Earthquake and Engineering Seismology, pp. 559-568, Academic Press, Amsterdam, 2002.

A. Jin (e-mail: ajin@bosai.go.jp) and K. Aki 